Revista de

Contabilidade e

Organizações

www.rco.usp.br
DOI: http://dx.doi.org/10.11606/rco.v7i19.55517
Journal of

Accounting and

Organizations

www.rco.usp.br

\title{
Efeitos do regime tributário de transição na carga tributária das companhias brasileiras
}

Helio Rieger de Mello ; Bruno Meirelles Salotti ${ }^{\mathrm{b}}$

${ }^{a}$ Auditor da Receita Federal do Brasil

${ }^{b}$ Faculdade de Economia, Administração, Contabilidade e Atuária- Universidade de São Paulo

\section{Informações do Artigo}

Histórico do Artigo

Recebido: 18 Novembro de 2012

Aceito: 07 Outubro de 2013

Palavras chave

Lucro contábil

Lucro fiscal

Regime Tributário de Transição

\section{Resumo}

A Lei $n^{\circ} 11.638 / 07$ iniciou a convergência da contabilidade brasileira para as normas internacionais do IASB promovendo, entre outras, uma relevante modificação: a implementação da ampla hegemonia da essência sobre a forma dito de outro modo, a prevalência da visão econômica na contabilidade financeira -, enquanto se manteve na contabilidade fiscal, majoritariamente, a predominância da perspectiva civil, que de forma inversa, privilegia a forma. Como os efeitos das novas regras contábeis causariam impacto positivo, nulo ou negativo no lucro tributário, a partir de 2008, foi instituído o Regime Tributário de Transição-RTT, com o objetivo de neutralizar-se todos os novos critérios de reconhecimento de receitas, despesas ou custos. As empresas ainda puderam, no biênio 20082009, optar ou não por esse novo regime, mas, a partir de 2010, sua adoção se tornou obrigatória. Entretanto, tratou-se de decisão difícil, principalmente, porque o prazo original era até $16 / 10 / 2009$, quando o último trimestre ainda não estava encerrado e, também, pela insegurança na interpretação das novas normas contábeis e dos seus efeitos na legislação fiscal. O objetivo principal deste artigo é avaliar se houve redução da carga tributária com a não opção pelo RTT. Para tal, analisou-se o efeito do RTT nos resultados fiscal e contábil dos anos de 2008 e 2009 em comparação com a média no período de 2005 a 2007 para as empresas de lucro real que não optaram por esse regime, discriminados pelos quatro setores: agricultura, comércio, indústria e serviços. A metodologia baseouse nos dados de 2005 a 2009, autorizados pela Receita Federal do Brasil, e a amostra pesquisada foi composta por 69.712 empresas de lucro real $(65 \%)$ que não optaram pelo RTT. Em 13/04/2010, a IN RFB n ${ }^{\circ} 1.023 / 10$ reabriu o prazo para opção, mas apenas 973 empresas modificaram a opção - de não para sim - pelo RTT que sugere uma boa análise dos contadores. A partir da comparação dos períodos 2008-2009 com 2005-2007, foram apurados os valores de cinco variáveis, quais sejam, receita e lucro brutos, lucros fiscal e contábil e a diferença entre os dois últimos e foram encontradas evidências estatísticas com base no teste de Wilcoxon de que as empresas que não optaram pelo RTT pagaram menos IRPJ e CSLL em 2008-2009.

Copyright (C) 2013 FEA-RP/USP. Todos os direitos reservados

\section{INTRODUÇ̃̃̃O}

A Lei $\mathrm{n}^{\circ} 11.638$, publicada em 28/12/2007, promoveu diversas alterações na Lei $n^{0}$ 6.404/76, aplicada às Sociedades Anônimas - S.A. e iniciou a convergência das normas contábeis para o padrão do International Accounting Standards Board - IASB, que é seguido por quase todas as nações européias e, também por outros

Autor Correspondente: Tel +55 11 3091-5820

E-mail : heliormello@hotmail.com (E. Bitti); brunofea@usp.br (B. M. Salotti)

Universidade de São Paulo, Faculdade de Economia Administração e Contabilidade, Departamento de Contabilidade Atuária. Av. Prof. Luciano Gualberto, 908 - FEA3 Cidade Universitária 05508-900 - Sao Paulo, SP - Brasil países, que totalizam mais de uma centena ${ }^{1}$. A Medida Provisória - MP n ${ }^{\circ} 449 / 08$, posteriormente transformada na Lei $\mathrm{n}^{\circ} 11.941 / 09$, bem como a Comissão de Valores Mobiliários - CVM e demais órgãos reguladores, continuaram esse caminho de adequação das normas contábeis brasileiras para os padrões internacionais. Uma importante modificação foi a definitiva separação entre a contabilidade fiscal e a financeira, o que tornou possível que cada uma seguisse os seus princípios para a apuração do resultado, mesmo que, na maioria das situações, as receitas e as despesas, aqui incluídos os custos, fossem coincidentes. Outra alteração relevante foi a ampla adoção da essência sobre a forma na contabilidade societária brasileira, que trouxe como consequência um patrimônio, bem como seus resultados, sob um enfoque

1. Iudícibus et al (2010, p. 15). Mas a maior parte desses países exigem esse padrão contábil apenas para as empresas S.A. de capital aberto. 
predominantemente econômico, e não mais civil, que antes vigorava e segundo o qual predomina a forma sobre a essência.

Dessa forma, o lucro ${ }^{2}$ contábil assenta-se na estrutura conceitual estabelecida pelo Pronunciamento Conceitual Básico da Contabilidade - também conhecido por CPC "00" - emitido pelo Comitê de Pronunciamentos Contábeis - CPC, em 2008. Segundo esse documento, o regime de competência e a primazia da substância sobre a forma são imprescindíveis para a apuração do resultado ${ }^{3}$.

Por outro lado, o lucro fiscal funda-se na Constituição Federal e também nas normas infraconstitucionais, que, no Brasil, seguem, predominantemente, o regime do direito romano - a legislação enuncia praticamente todos os critérios necessários e suficientes para a vigência da norma tributária -, em oposição à contabilidade, que se pauta nos princípios definidos pela sua estrutura conceitual e demais normas contábeis (que também, em geral, são baseadas em princípios).

Seguindo esse preceito do direito tributário, a legislação sobre o Imposto de Renda das Pessoas Jurídicas - IRPJ e sobre a Contribuição Social sobre o Lucro Líquido - CSLL, tributos que incidem sobre o resultado, parte do lucro contábil e, como segue caminho próprio, prescreve ajustes, exclusões e compensações para, por fim, chegar ao lucro fiscal, que é a base de cálculo desses dois tributos.

Como as alterações no lucro contábil que não fossem ajustadas pela legislação fiscal teriam reflexos diretos na base de cálculo desses dois tributos, foi instituído, em 2008, o Regime Tributário de Transição-RTT ${ }^{4}$, com o intuito de serem neutralizados esses efeitos no lucro tributário, a partir do ano-base 2008, e, ao mesmo tempo, permitiu que as regras tributárias fossem as mesmas vigentes até 31/12/2007. Assim, por exemplo, uma nova regra contábil, que, instituída pela Lei $\mathrm{n}^{\circ} 11.638$, representasse uma receita, aumentaria o lucro contábil, mas não afetaria o lucro fiscal, pois, para este, valeriam as normas tributárias de reconhecimento das receitas vigentes em 31/12/2007, ocorrendo, dessa forma, a neutralidade tributária.

Considerando que essas modificações contábeis no reconhecimento de receitas, despesas e custos poderiam causar impacto no resultado, de forma positiva, neutra ou negativa, o RTT, que foi opcional para o biênio 2008-2009 e obrigatório a partir de 2010, fez com que os estudos realizados pelos contadores - que foram profundos em virtude do prazo estabelecido para essa opção e, também, da insegurança que sentiam esses profissionais ao interpretar algumas transações sobre esses efeitos tributários - tivessem papel preponderante para as empresas.

Considerando essa diferença conceitual entre os lucros contábil e fiscal, é importante inquirir os efeitos das modificações contábeis nos resultados dos anos

2. Este trabalho utilizará o termo lucro na acepção de resultado, que abrange também o prejuízo (também usado como lucro líquido negativo).

3. A referida Estrutura Conceitual foi revisada em 2011 pelo CPC em consequência das alterações da Estrutura Conceitual emitida pelo IASB. Porém, a versão de 2011 não é abordada nesse trabalho pois os dados pesquisados se referem a períodos anteriores.

4. A neutralidade tributária já estava prevista na Lei $n^{\circ} 11.638 / 07$, mas não de forma tão contundente como no RTT, instituído pela MP $449 / 08$, que foi convertida na Lei $n^{\circ} 11.941 / 09$. de 2008 e 2009, quando entrou em vigor o RTT, que ainda era optativo, para as empresas de lucro real que não optaram por esse regime, com discriminação pelos setores agricultura, comércio, indústria e serviços, bem como avaliar os efeitos da IN RFB n ${ }^{\circ} 1.023$.

Destarte, o objetivo geral é avaliar se houve redução da carga tributária das empresas que não optaram pelo RTT. Para tal, analisa-se o efeito do RTT nos resultados fiscal e contábil dos anos de 2008 e 2009, em comparação com a média no período de 2005 a 2007, para as empresas de lucro real que não optaram por esse regime, com discriminação pelos setores agricultura, comércio, indústria e serviços. Além disso, serão investigados: (i) averiguar qual a quantidade de empresas de lucro real que não optou pelo RTT e sua participação no total de empresas desse regime de apuração de lucro; (ii) identificar a quantidade das empresas de lucro leal que retificou a DIPJ no período de 13/04/2010 a 31/12/2010, referentes ao ano-base 2008, e no período de 26/12/2008 a 14/09/2009, do ano-calendário 2007; e (iii) apurar o número de empresas de lucro real que, após entregar a DIPJ original do ano-base 2008 como não optantes pelo RTT, retificou essa declaração para optar por esse regime, a partir da vigência da IN RFB n ${ }^{\circ} 1.023$, em 13/04/2010.

As principais justificativas para este estudo são: 1) quantificar o número de empresas que optaram pelo RTT, pois temia-se um aumento da carga tributária sem esse Regime; 2) constatar se as empresas de lucro real que não optaram pelo RTT apresentaram no período 20082009 um lucro fiscal proporcionalmente inferior ao da média de 2005 a 2007; 3) identificar os efeitos das novas normas contábeis - com enfoque predominantemente econômico e não mais civil - em importantes indicadores econômicos representados pela receita e lucro bruto, lucros contábil e fiscal e a diferença entre esses dois últimos; 4) Esses efeitos no lucro tributário são muito importantes, pois a neutralidade tributária prevista pelas Leis $n^{\circ} 11.638 / 07$ e 11.941/09 não impede a inclusão na hipótese de incidência do IRPJ e CSLL de novas receitas, despesas ou custo, instituídos pela convergência para a contabilidade internacional; 5) apurar a validade da introdução da Instrução Normativa $\mathrm{n}^{\circ} 1.023 / 10$, bem como detectar indícios da qualidade no trabalho dos contadores; 6) a partir da autorização da Receita Federal do Brasil, ter tido condições de realizar um estudo relevante numa vasta base de dados de cinco anos, sem infringir o sigilo fiscal.

\section{REFERENCIAL TEÓRICO}

Conforme já citado na seção anterior, o RTT veio para promover a neutralidade tributária, ou seja, o intuito era o de garantir que as mudanças nos padrões contábeis não provocassem aumento nem redução de tributos. Apesar dessa garantia de neutralidade fiscal, muitas empresas tinham dúvidas acerca da interpretação que a Receita Federal do Brasil - RFB faria de alguns efeitos tributários - amortização do ágio, cálculo dos juros sobre o capital próprio, novas taxas de depreciação inferiores às anteriores - e, até mesmo, da possibilidade de as novas regras contábeis causarem aumento nos tributos a pagar. Outrossim, aumentou a insegurança das empresas o fato de a opção para 2008 ser válida também para 2009 e de ter sido feita até 16/10/2009 (data da entrega da Declaração de Informações Econômico Fiscais da Pessoa 
Jurídica - DIPJ).

Mas uma importante medida para reduzir esse cenário de insegurança das empresas na opção ou não pelo RTT foi adotada pela Receita Federal do Brasil com a edição da Instrução Normativa - IN RFB $n^{\circ}$ 1.023 , publicada em $13 / 04 / 2010$, que permitiu que os contribuintes que entregaram a DIPJ original, no prazo inicialmente determinado, qual seja, 16/10/2009, quando o biênio ainda não estava encerrado ${ }^{5}$, e o fizeram como não optantes, tivessem a possibilidade de entregar uma declaração retificadora mudando para optante pelo RTT ${ }^{6}$. Com a adoção dessa medida, parte $^{7}$ da instabilidade na escolha desse regime estava encerrada e atendida uma demanda manifestada pelas empresas.

Os impactos causados pelas alterações contábeis nos lucros fiscal e societário foram pouco estudados no Brasil em decorrência, principalmente, da proximidade temporal dessas modificações e, também, do sigilo fiscal, particularmente na primeira forma de lucro. Esses efeitos são muito importantes, pois a neutralidade tributária prevista pelas Leis $n^{\circ} 11.638 / 07$ e 11.941/09 não impede a inclusão na hipótese de incidência do IRPJ e CSLL de novas receitas, despesas ou custo, instituídos pela convergência para a contabilidade internacional, desde que sejam feitas através de leis que não afrontem a Constituição Federal e o Código Tributário Nacional - CTN. No trecho abaixo transcrito Mosquera e Lopes (2010, p. 80) corroboram esse ponto de vista:

Essa neutralidade, no entanto, não significa que a legislação tributária e as autoridades fiscais não podem se valer de conceitos trazidos pela contabilidade internacional. Isso, no entanto, deve ser feito de forma explícita pelos meios legais competentes respeitando o princípio da legalidade e da tipicidade - tão importantes na seara tributária. Não está no escopo deste artigo, mas é uma discussão importante, saber se a legislação tributária deveria ou não se valer dos conceitos da nova contabilidade. Esse é, com certeza, um tema para futuras incursões.

No exterior, especialmente na Europa, em que as IFRS já vêm sendo adotadas desde 2005, diversas pesquisas têm sido conduzidas para estudar as mudanças dos padrões contábeis e os potenciais efeitos fiscais decorrentes de tais mudanças. Essas pesquisas, descritas na seção 2.3 deste artigo, demonstram a relevância desse tema e a constante preocupação dos mercados sobre as consequências tributárias da adoção das IFRS.

Os tributos sobre o lucro, como o próprio nome induz, são calculados a partir dos resultados das companhias. Sendo assim, é importante entender os conceitos relativos aos lucros contábil e fiscal, para avaliar a diferença entre os mesmos e seus impactos fiscais.

\subsection{Lucro contábil}

\section{A opção era cumulativa para os anos de 2008 e 2009.}

6. O inverso, mudar de optante para não optante pelo RTT, não foi permitido.

7. Quase todas as dúvidas relacionadas com a interpretação pela RFB, das questões destacadas no parágrafo anterior ainda persistiam em dezembro de 2010, quando foram extraídas as DIPJs.
O processo contábil pode ser dividido em três fases: i) reconhecimento; ii) mensuração; e iii) divulgação. Lopes e Martins (2005, p. 51) corroboram esse entendimento quando afirmam:

O primeiro passo na investigação da teoria da contabilidade neste texto está ligado à definição exata do fenômeno que está sendo estudado. Chamaremos esse fenômeno de processo contábil. Esse processo é caracterizado por três fases: reconhecimento, mensuração e evidenciação. Nosso objeto de estudo refere-se a qualquer ação de natureza econômica que envolva uma dessas três etapas. Elas não precisam estar necessariamente organizadas nessa ordem. Em alguns casos somente uma ou duas ocorrem. Não importa. Desde que uma delas esteja presente, a análise poderá ser aplicada.

A primeira fase identifica o fenômeno econômico e destaca a importância da interpretação da essência em detrimento da forma para uma adequada contabilização. Com base nessa concepção, o profissional contábil não pode ser o único responsável pelo registro das operações, pois há outros envolvidos com condições mais efetivas para interpretá-lo. Por exemplo, o cálculo da depreciação deve contar com a participação daquele que efetivamente conhece e acompanha o ativo imobilizado.

A etapa da mensuração dos eventos econômicos é a da precificação que, de forma geral, especialmente no reconhecimento inicial, adota o custo histórico. Dado este muito importante para outras ciências, entre elas o direito, conforme relata Weffort (2005, p.106).

Na última etapa, a divulgação de relatórios subsidiará o processo de tomada de decisões dos diversos interessados. Por exemplo, um dos produtos finais da contabilidade tributária é a DIPJ.

O item mais demandado pelos usuários desses relatórios contábeis é o lucro, que, como um conceito simplório, é definido como o resultado da diferença entre receitas e custos e despesas em um período, baseado na estrutura conceitual para a elaboração e apresentação das demonstrações contábeis, como enfatizam Lopes e Martins (2005, p.36).

Essa estrutura conceitual da contabilidade é o alicerce para a elaboração dos relatórios contábeis, descrevendo, basicamente, seus pressupostos básicos, suas características qualitativas (princípios), suas limitações, seus elementos (ativos, passivos, despesas e receitas) e seus critérios de reconhecimento. Numa analogia com o direito, a estrutura conceitual funciona como a Constituição Federal, que estabelece as diretrizes para o legislador infraconstitucional.

Duas características muito importantes desse Pronunciamento são a prevalência da essência sobre a forma e o não detalhamento das normas que influenciam o resultado (lucro ou prejuízo), dado que demandam um julgamento mais acurado por parte do contador, que, consequentemente, dará suporte à elaboração de lucros contábeis mais fidedignos, o que será de maior utilidade a todos os interessados.

Já o pressuposto básico do regime de competência talvez seja aquele que, de forma objetiva, maior influência exerce sobre o lucro contábil, favorecendo, assim, uma maior previsão dos fluxos futuros de caixa.

Seguindo essas diretrizes, o lucro deve pautar-se no 
pressuposto básico do regime de competência que prevê o reconhecimento quando ou enquanto ocorre o evento, não ficando adstrito à sensibilização do caixa da empresa.

A estrutura conceitual da contabilidade demarcou a natureza dos seus dois principais elementos do lucro, tal como preceitua o Pronunciamento Conceitual Básico (2008, p.21) quando estabelece:

a) Receitas: são aumentos nos benefícios econômicos sob a forma de entrada de recursos ou aumento de ativos ou diminuição de passivos, que resultam em aumentos do PL e que não sejam provenientes de aporte dos proprietários da entidade;

b) Despesas: são decréscimos nos benefícios econômicos sob a forma de saída de recursos ou redução de ativos ou incrementos em passivos, que resultam em decréscimo do PL e que não sejam provenientes de distribuição aos proprietários.

Embora essa definição de receita seja correta, ela é muito concisa, entretanto, o CPC 30 (receitas) detalha muito bem seu conceito, momento do seu reconhecimento, formas de mensuração etc.

O conceito de despesa previsto na estrutura conceitual da contabilidade, por sua vez, deveria ser um pouco mais amplo, uma vez que aborda apenas os efeitos no patrimônio, segundo observa Hendriksen e Breda (2007, p. 232).

Além da descrição da natureza desses elementos que compõem o lucro, são fixados critérios para o reconhecimento de receitas e despesas, que devem atender aos pressupostos do provável benefício econômico futuro, entre os quais a mensuração de seu valor em bases confiáveis, que a estrutura conceitual da contabilidade fornece quatro bases para determinar seu reconhecimento: i) custo histórico; ii) custo corrente; iii) valor realizável; e iv) valor presente.

Esse lucro apurado nas condições estabelecidas pela contabilidade é o ponto de partida para a apuração do lucro fiscal que, por sua vez, se baseia na legislação tributária. O lucro contábil, gênero, é composto, principalmente, pelas espécies bruto, operacional, antes da CSLL e IRPJ e líquido. O penúltimo é o ponto de partida para a determinação do lucro real, que, seguida da dedução desses tributos e das participações, chega ao lucro líquido. Este trabalho utiliza o termo lucro contábil no mesmo sentido que era conferido ao lucro antes da CSLL e IRPJ, que é a base para a apuração do lucro real.

\subsection{Lucro fiscal}

A regra-matriz define todas as condições necessárias para a descrição do fato gerador do tributo e, igualmente, antevê e apresenta todas as consequências da obrigação que advém da norma ${ }^{8}$. Essa ferramenta é semelhante a

8. No caso da apuração do ajuste anual do IRPJ (a da CSLL é muito semelhante) a regra-matriz seria:

a) critério material: apurar lucro real;

b) critério espacial: universal (tributação em bases universais);

c) critério temporal: ano-calendário;

d) sujeito ativo: União;

e) sujeito passivo: contribuinte que apurar o lucro - pessoa jurídica ou assemelhado;

f) base de cálculo: lucro real; uma fórmula matemática e facilita sobremaneira a análise da norma tributária devido ao seu elevado poder de síntese, conforme explicado por Carvalho (2000, p.236).

Um dos critérios necessários para a validade de uma regra tributária é o fato gerador, que é a hipótese descrita pela norma, a qual com a ocorrência da situação fática no mundo real faz nascer a obrigação tributária. Também chamada de hipótese tributária, sua ocorrência no que concerne ao Imposto de Renda dá-se com a disponibilidade econômica ou jurídica: (i) do produto do capital; (ii) do produto do trabalho; (iii) do produto da combinação entre capital e trabalho; (iv) de acréscimos patrimoniais sem origem nem no capital nem no trabalho nem em ambos.

O Imposto de Renda das Pessoas Jurídicas pode ser apurado, basicamente, nas modalidades de lucro real, presumido, arbitrado e simples nacional ${ }^{9}$.

No caso do lucro real, regime tributário que será aprofundado neste estudo, parte do lucro líquido apurado na contabilidade societária ${ }^{10}$ - na realidade, ele é anterior à CSLL e ao próprio IRPJ -, que é ajustado pelas adições, exclusões ou compensações prescritas ou autorizadas pela legislação tributária. $\mathrm{O}$ artigo 248 do Regulamento do Imposto de Renda de 1999 - RIR/99 estabelece que o lucro líquido do período de apuração é a soma algébrica do lucro operacional, dos resultados não operacionais ${ }^{11}$ e das participações, e deverá ser determinado com a observância dos preceitos da lei comercial. Dessa forma, o lucro apurado na contabilidade não é o lucro fiscal, mas, sim, o ponto de partida para a apuração do lucro real.

O RIR admite que as despesas operacionais usuais ou normais para a atividade da empresa são dedutíveis na apuração do IRPJ, ou seja, não precisam ser anuladas, compondo-se assim o lucro tributário. Entretanto, há algumas exceções como: despesas com alimentação de sócios, acionistas e administradores; despesas com brindes; despesas com provisões, exceto as expressamente autorizadas pelo RIR/1999 (art. 335); provisão para créditos de liquidação duvidosa (respeitados os limites da legislação fiscal) etc.

O mecanismo de anulação dessas despesas operacionais, que foram consideradas na contabilidade, mas que não são aceitas na apuração do lucro fiscal, não consistirá num estorno na contabilidade, mas, sim, numa adição no Livro de Apuração do Lucro Real - LALUR.

Sob o enfoque da contabilidade societária, todas as despesas que afetem o resultado devem ser contabilizadas, no intuito de se atender ao princípio da prudência. Já a legislação fiscal não permite a dedução das despesas que não sejam necessárias à percepção da receita ou à manutenção da fonte produtora da base de cálculo do Imposto de Renda. Esse impedimento não se restringe às despesas, uma vez que abarca custo, encargo, provisão, participação e perda, pois, além das restrições já citadas, tem a intenção também de não querer incentivar alguns g) alíquota: $15 \%$, e adicional de $10 \%$ sobre o lucro acima de $20 \mathrm{mil}$ reais mensais ou equivalentes.

9. Há outras formas de tributação adotadas em menor escala: real/ arbitrado, presumido/arbitrado, presumido/real, presumido/real/arbitrado, imune e isenta.

10. Mesmo que não seja uma empresa S.A., se optar pela apuração do lucro real, deve seguir a legislação societária conforme previsão do Decreto-lei no ${ }^{\circ} 1.598 / 1977$.

11. A Lei $\mathrm{n}^{\circ} 11.638 / 07$ extinguiu esse grupo e incluiu os resultados não operacionais em outros resultados operacionais. 
fatos, reduzir os planejamentos tributários e, até mesmo, evitar fraudes.

As exclusões autorizadas pela legislação fiscal têm o efeito inverso ao das adições, pois, reduzem a base tributável de duas formas: $1^{\text {a }}$ ) valores cuja dedução seja autorizada pela legislação tributária e que não tenham sido computados na apuração do lucro líquido do exercício; $2^{\mathrm{a}}$ ) resultados, rendimentos, receitas $\mathrm{e}$ quaisquer outros valores incluídos na apuração do lucro líquido que, de acordo com a legislação tributária, não sejam computados no lucro real.

O terceiro ajuste sobre o lucro líquido no intuito de apurar o lucro real, além das adições e exclusões, são as compensações de prejuízos fiscais, apurados no ano atual e em anteriores. Estes limitados a 30\% do lucro líquido do exercício em que está sendo deduzido, e não do ano em que foi levantado esse prejuízo, ajustado pelas adições e exclusões.

\subsection{A diferença entre os lucros contábil e fiscal}

A diferença entre essas duas formas de resultado já existia antes mesmo da sua efetiva separação iniciada pela Lei $\mathrm{n}^{0} 11.638 / 07$, uma vez que cada uma se apoia em bases distintas. O lucro contábil segue os princípios contábeis, enquanto o resultado fiscal está sob a égide da Constituição Federal e das leis infraconstitucionais. Mas havia mais coincidências do que discrepâncias, pois esses alicerces privilegiavam a forma em detrimento da essência, sob um panorama civil.

Esse cenário modificou-se, a partir de 2008, com a edição da Lei $\mathrm{n}^{\circ} 11.638 / 07$, porquanto a contabilidade societária passou a considerar uma visão econômica dos fatos, reconhecendo a predominância da substância sobre a forma, e a tributação continuou, na maioria das vezes, com a perspectiva civil - maneira como a legislação fiscal define o evento econômico. Assim, o contribuinte deve ajustar essa dicotomia de perspectivas no Programa Validador e Assinador da Entrada de Dados para o Controle Fiscal Contábil de Transição FCONT, que produzirá a contabilidade fiscal baseada, fundamentalmente, no negócio jurídico.

Deste modo, essa divergência precisa ser reexaminada e alguns estudos já foram realizados em outros países. Mas seus resultados não podem ser adotados apenas sob a ótica aritmética da diferença entre esses dois resultados, pois a tributação não deve ensejar a emergência da subjetividade, tal como assinala Calijuri (2011, p. 187).

Alguns autores, de vários países, debruçaram-se sobre essa diferença, com destaque para Formigoni et al (2009); Goncharov e Zimmermann (2005); Mills (1998); Tang (2005); Tzovas (2006); Guenther et al (1997) e Manzon e Plesko (2002). A literatura internacional define essa discordância como Book-Tax Differences - BTD.

De acordo com Tang (2005), essa divergência entre os resultados contábil e fiscal pode ter origem em diferenças permanentes e/ou temporárias. Aquelas são decorrentes de receitas ou despesas consideradas na contabilidade, mas que são anuladas para fins fiscais. Já no que concerne às diferenças temporárias, o efeito da receita ou despesa é o mesmo tanto na contabilidade financeira como na fiscal, embora haja divergência no que concerne ao momento desse reconhecimento.
Assim a diferença entre os lucros contábil e tributário - Book-Tax Differences - BTD -, baseada exclusivamente na divergência entre a norma contábil e a tributária, é classificada como diferenças não-discricionárias ou BTD normal - NBTD -, ao passo que, quando o gestor atua adotando critérios alternativos, previstos nas normas contábeis e fiscais, como, por exemplo, nos accruals ${ }^{12}$, a consequência será uma diferença discricionária ou BTD anormal - ABTD. Neste caso, a origem dessa divergência é o gerenciamento contábil e/ou fiscal.

Com as recentes mudanças nos padrões contábeis decorrentes da adoção das IFRSs, há uma tendência, $a$ priori, de aumento dessa diferença entre lucros contábil e fiscal. Por conta disso, esse tema tem despertado interesse dos pesquisadores em conhecer os potenciais efeitos fiscais da adoção dos padrões internacionais de contabilidade.

Notadamente na Europa, em que se adotam as IFRSs desde 2005, esse assunto já tem resultado em diversas publicações, com análises sob diferentes perspectivas. Destacam-se os trabalhos de Eberhartinger e Klostermann (2007), Gee, Haller e Nobes (2010), Haverals (2007), Istrate (2012), Kager, Schanz e Niemann (2011), Karampinis e Hevas (2013), Kirsch e Olsson (2008) e Madalina, Nadia e Catalin (2011). Esses trabalhos estudaram os mercados da Áustria, Alemanha, Reino Unido, Bélgica, Romênia, Grécia e Suécia.

Alguns desses trabalhos relatam a pressão que a mudança no padrão contábil causa nas regras fiscais (ver por exemplo MADALINA, NADIA e CATALIN, 2011 e ISTRATE, 2012) e a preocupação de que a adoção das IFRS cause aumento da carga tributária efetiva (HAVERALS, 2007).

Em outros casos, foram analisados os efeitos fiscais que a adoção das IFRS provocou em determinados mercados. Gee, Haller e Nobes (2010) relatam que, após a adoção das IFRS tanto na Alemanha quanto no Reino Unido, a influência fiscal sobre as divulgações financeiras consolidadas em IFRS ficou muito mais fraca. Karampinis e Hevas (2013) analisaram práticas de gerenciamento de resultado nas companhias do mercado grego e demonstraram que a pressão fiscal é um determinante negativo significativo das acumulações discricionárias no período pré-IFRS. Entretanto, esse efeito foi dissipado após a adoção do padrão internacional.

Há ainda relatos que evidenciam que a adoção das IFRS tem pouco potencial para produzir efeitos no lucro tributável (ver KIRSCH e OLSSON, 2008; e EBERHARTINGER e KLOSTERMANN, 2007).

Em outro estudo, já no mercado chinês, Chan, Lin e Tang (2013) estudaram os incentivos de divulgação financeira e as consequências fiscais e relatam a preocupação de que a adoção das IFRS pode trazer consequências não intencionais para a arrecadação tributária. Já nos EUA, Rood e Kinney (2008) discutem os potenciais impactos tributários da adoção das IFRS no mercado norte-americano, mesmo tais normas não sendo obrigatórias.

Essas evidências empíricas demonstram a relevância do tema em perspectiva internacional. No Brasil, isso não é diferente, porém, o processo é mais recente. Com a adoção da Lei N.11.638/07, houve diversas alterações

12. É o ajuste para a adoção do regime de competência em detrimento do regime de caixa, que redunda na diferença entre o lucro contábil e o fluxo de caixa. 
nas normas contábeis a partir de 2008 com potenciais impactos tributários. Na seção seguinte, são descritas de forma sucinta tais mudanças.

\subsection{Novas normas contábeis}

As alterações contábeis que entraram em vigor no ano de 2008 e que poderiam introduzir novos critérios de reconhecimento de receita, despesa ou custo foram as seguintes:

1) Redução ao valor recuperável de ativos - impairment: introduzida pelo CPC $01^{13}$ obrigou as empresas a analisarem, periodicamente, o valor de recuperação dos seus ativos imobilizados e intangíveis, podendo gerar despesas, quando comprovado que não poderão produzir resultados suficientes para recuperação desse valor, ou uma reversão de despesa limitada ao valor contábil anterior, quando, no passado, já tenha sido contabilizada uma perda.

2) Efeitos das mudanças nas taxas de câmbio e conversão de demonstrações contábeis: o CPC 02 define os procedimentos de avaliação e mensuração dos resultados de investimentos localizados no exterior. Uma das principais modificações que envolvem as contas de resultado é o reconhecimento da variação cambial, no método de equivalência patrimonial, apenas quando a investida do exterior estiver sendo baixada. Enquanto, isso não ocorrer, há impacto no PL, na conta ajuste de avaliação patrimonial. Até o ano de 2007, antes da vigência desse CPC, a variação cambial causava impacto diretamente no resultado do exercício.

3) Ativo intangível com maior restrição: o CPC 04 definiu que os ativos intangíveis com vida útil definida continuam sendo amortizados, mas aqueles com vida útil indefinida não mais o seriam. Em ambos os casos há aplicação do teste de impairment. A partir de 2009, o CPC 13 extinguiu a amortização do ágio fundamentado em rentabilidade futura, denominado de goodwill.

4) Operações de arrendamento mercantil - leasing: o CPC 06 modificou completamente a contabilização dessa operação lastreada num dos principais alicerces da Lei $\mathrm{n}^{\circ} 11.638 / 07$, que é a prevalência da essência sobre a forma. Nessa nova sistemática ${ }^{14}$ para o leasing financeiro, a empresa arrendatária, apesar de ter a posse e não a propriedade, registrará o bem no ativo (com suas depreciações) e a dívida no passivo (com as despesas de juros e de amortizações do principal), tudo em decorrência de sua essência deter os riscos e benefícios desse bem. Já a arrendadora contabilizará os valores a receber, atualizados a valor presente, e reconhecerá, mensalmente, os juros como receita financeira e os recebimentos

13. Os CPC citados nos itens deste parágrafo detalharam essas modificações, mas na realidade, elas foram promovidas pelas seguintes normas: Lei $n^{\circ} 11.638 / 07$, MP 449/08 e/ou Lei no ${ }^{\circ} 11.941 / 09$.

14. Antes, registrava apenas as despesas com o arrendamento mercantil. do principal $^{15}$ como redução dos valores a receber.

5) Subvenção e assistência governamentais: o CPC 07 passou a exigir que as doações e subvenções recebidas transitassem obrigatoriamente pelo resultado (após cumpridas as obrigações vinculadas às doações e às subvenções recebidas), gerando, dessa forma, uma nova receita, se comparada com a sistemática anterior a 2008, que reconhecia esses recebimentos diretamente no patrimônio líquido, em conta de reserva de capital.

6) Prêmio na emissão de debêntures: alteração promovida pelo CPC 08 que passou a apropriar os gastos de captação, como, por exemplo, a contratação de uma empresa para a divulgação dessa emissão, como custo de captação, apropriando-o como receita pelo prazo de vigência das debêntures. Antes, esses gastos eram contabilizados diretamente como despesa na data da emissão.

7) Pagamento baseado em ações (stock options): o CPC 10 estabeleceu regras para o reconhecimento no resultado do exercício dos planos de incentivo a empregados e administradores lastreados em opções para aquisição de ações da própria companhia. Assim, esse reconhecimento, com base no valor justo dessas opções, poderá gerar uma despesa ou uma reversão de despesa com efeito de receita, no caso de revisão das estimativas já consideradas em anos anteriores.

8) Critérios para avaliação do ativo, relativamente às aplicações em instrumentos financeiros: o CPC 14 definiu que, quando $o$ instrumento financeiro se classificar como destinado à negociação ou disponível para venda, sua avaliação será pelo valor justo, que deverá gerar uma receita ou despesa, caso haja variação na comparação com o seu valor de custo de aquisição.

9) Elementos do ativo ou passivo, decorrentes de operações de longo prazo: o CPC 12 implementou essa nova regra que pode gerar receita ou despesa, caso o valor presente seja diferente do registrado anteriormente.

\section{METODOLOGIA}

Esta pesquisa possui propósitos exploratório e descritivo e adota uma abordagem metodológica empírico-positivista, de acordo com a classificação oferecida por Martins e Theóphilo (2009, p. 40).

Segundo Gil (2002), as pesquisas exploratórias têm como objetivo proporcionar maior familiaridade com o

15. Antes, o bem ficava no seu imobilizado e, conseqüentemente, era depreciado. Entretanto, o Banco Central ainda não adotou esse $\mathrm{CPC}$ e, dessa forma, as instituições financeiras não estão contabilizando de acordo com esse Pronunciamento. 
problema, com vistas ou a torná-lo mais explícito ou a constituir hipóteses.

Já as pesquisas descritivas, ainda segundo o autor, têm como objetivo primordial descrever as características de determinada população ou fenômeno ou, então, o estabelecimento de relações entre variáveis. Este trabalho possui essas características, pois analisa $73 \%$ das empresas não optantes pelo regime do RTT.

Os dados foram extraídos das DIPJ exercícios 2010 a 2006, que se referem aos anos-base 2009 a 2005, em dezembro de 2010, e a autorização para divulgação dessa pesquisa foi concedida formalmente pelo Secretário da Receita Federal do Brasil, desde que os dados estejam agregados, como, desde o início, era a intenção deste estudo. Dessa forma, pelo sigilo das informações fiscais, somente com essa autorização especial é que foi possível manipular todos esses dados antes de aglutiná-los nas tabelas exibidas neste trabalho.

É importante destacar que a autorização para realização desta pesquisa pela Receita Federal do Brasil permite a avaliação dos efeitos desse novo regime de tributação em importantes indicadores econômicos representados pela receita e lucro bruto, lucros contábil e fiscal e a diferença entre esses dois últimos.

As empresas sob o regime de tributação lucro real no ano-calendário 2008 totalizaram 146.213 e representaram $3,16 \%$ do total das empresas que apresentaram a DIPJ. Mas seu peso no total da receita bruta das empresas é substancial, com $84,87 \%$ do total da receita bruta das empresas que entregaram DIPJ no ano-base 2008.

Dessas empresas de lucro real, 95.059 não optaram pelo RTT, representando $65 \%$. Por conseguinte, as demais realizaram a opção por esse regime.

O RTT é aplicado ao IRPJ, CSLL, PIS-PASEP e COFINS, mas este estudo analisa o lucro fiscal, que é a base de cálculo para os dois primeiros ${ }^{16}$ tributos.

A definição de receita bruta para as empresas que se enquadraram como Pessoas Jurídicas em Geral no campo Qualificação da DIPJ foi respaldada pela IN RFB $n^{\circ}$ 964/09 que aprovou o Programa Gerador da Declaração PGD e as instruções (ajuda para preenchimento) da DIPJ do ano de 2008 que prevê no seu item 15.1.5.3 "A receita bruta das vendas e serviços compreende o produto da venda de bens nas operações de conta própria, o preço dos serviços prestados e o resultado auferido nas operações de conta alheia". Destarte, ela é composta pelas linhas 1 a 8 da ficha 06A (Demonstração do Resultado).

O lucro bruto dos anos 2005 a 2009 foi obtido do campo com esse mesmo termo, que, no ano-base 2008, encontra-se na ficha 06A, linha 17, e o lucro fiscal foi extraído da linha de Lucro Real após a Compensação dos Prejuízos do Próprio Período de Apuração (linha 73, ficha 09, da DIPJ exercício 2009 - ano-calendário 2008 ), não se considerando a compensação de prejuízos fiscais de anos anteriores. O lucro contábil é aquele informado na rubrica Lucro Líquido Antes da CSLL, que corresponde à linha 62 da DIPJ do exercício 2009, ano-base $2008^{17}$.

16. Na realidade, há pequenas diferenças entre as bases de cálculo do IRPJ e da CSLL que não serão exploradas neste estudo.

17. As instituições financeiras (fichas 06B e 09B) e as seguradoras (fichas 06C e 09C) possuem fichas específicas que também foram consideradas neste estudo, sem necessariamente possuírem o mesmo número de linha, mas com a mesma terminologia, como, por exemplo, o lucro contábil da ficha 06A, linha 62, está disposto na
Com a finalidade de tornar exequível uma adequada comparação entre esses dois períodos, 2008-2009 e 2005-2007, foram excluídas as empresas que não apresentaram, em pelo menos um ano, valores diferentes de zero para receita total ${ }^{18}$ ou lucros fiscal e contábil, em cada um desses dois momentos. Desse modo, um contribuinte com lucros fiscal e contábil iguais a zero e receita total de 10 milhões de reais nos anos 2008 e 2007 e zero nos demais, comporia, por exemplo, a amostra. De outra forma, se no caso anterior ele apresentasse zero no ano 2008 ou 2007, seria excluído deste estudo.

Após esses ajustes, a amostra ficou reduzida a 69.712 empresas, quantidade esta bastante significativa, dado que representa $48 \%$ de todas as empresas de lucro real e $73 \%$ das não optantes por esse regime de tributação.

O cálculo da variação de $12,34 \%$ do Índice Nacional de Preços ao Consumidor Amplo - IPCA, entre os períodos 2005-2007 e 2008-2009, foi realizado pela média dos IPCAs Números Índices de 01/2008 a 12/2009, dividido pela média de 01/2005 a 12/2007 ${ }^{19}$.

Para avaliar o objetivo principal - redução da carga tributária das empresas que não optaram pelo RTT - foi realizado, no programa Statistical Package for the Social Sciences - SPSS, o teste não paramétrico de Wilcoxon de diferenças de médias para dados emparelhados. Foram comparadas as médias dos lucros fiscais dos dois períodos analisados, 2005 a $2007(\mu 1)$ e 2008 a 2009 $(\mu 2)$. As hipóteses do teste estatístico são as seguintes:

$$
\mathrm{H} 0: \mu 1=\mu 2
$$

$$
\mathrm{H} 1: \mu 1 \neq \mu 2
$$

Para a análise dos efeitos econômicos causados pela IN RFB n ${ }^{\circ} 1.023 / 2010$, são consideradas as DIPJ 2009 , ano-base 2008, retificadas entre 13/04/2010 e 31/12/2010 e as declarações do ano anterior, calendário 2007, precisamente o período que se estende de 26/12/2008 a $14 / 09 / 2009$

Dessa forma, o intervalo de tempo de retificação é proporcional entre as DIPJ desses dois anos, pois foi considerado o mesmo número de dias a partir da data da entrega, da vigência da $\mathrm{IN}$ e da data final do período de retificação.

\section{RESULTADOS}

4.1. Análises dos anos 2005-2007 comparativamente aos anos 2008-2009

linha 70 da ficha $06 \mathrm{~B}$.

18. DIPJ ano-base 2008, ficha 06A, linhas 1 a 8,18 a 34 e 51 a 53 , com as correspondentes para as instituições financeiras (ficha 06B) e seguradoras (ficha 06C).

19 Disponível em < http://www.ibge.gov.br/home/estatistica/indicadores/precos/inpc_ipca/ipca-inpc_201106_1.shtm $>$. Acesso em 22/07/2011. 
Tabela 1 Valores médios (R\$ mil) por setor nos anos-base 2005 a 2007 com IPCA de 12,34\%

\begin{tabular}{c|c|c|c|c|c|c}
\hline Setor & $\begin{array}{c}\text { Quantidade de } \\
\text { empresas }\end{array}$ & Receita bruta & Lucro bruto & Lucro fiscal & Lucro contábil & $\begin{array}{c}\text { Diferença lucros } \\
\text { fiscal e contábil }\end{array}$ \\
\hline Agricultura & 1.128 & 7.820 .625 & 927.813 & -556.881 & -270.163 & -286.719 \\
\hline Indústria & 13.808 & 226.507 .417 & 39.622 .501 & 1.203 .879 & 2.069 .688 & -865.809 \\
\hline Comércio & 30.307 & 340.956 .083 & 44.612 .371 & 3.428 .923 & 3.631 .158 & -202.235 \\
\hline Serviço & 24.469 & 189.275 .512 & 43.172 .528 & 2.619 .229 & 4.057 .631 & -1.438 .402 \\
\hline Total & 69.712 & 764.559 .637 & 128.335 .214 & 6.695 .150 & 9.488 .315 & -2.793 .165 \\
\hline
\end{tabular}

Tabela 2. Valores médios (R \$ mil) por setor nos anos-base 2008 e 2009

\begin{tabular}{|c|c|c|c|c|c|c|}
\hline Setor & $\begin{array}{l}\text { Quantidade de } \\
\text { empresas }\end{array}$ & Receita bruta & Lucro bruto & Lucro fiscal & Lucro contábil & $\begin{array}{l}\text { Diferença lucros } \\
\text { fiscal e contábil }\end{array}$ \\
\hline Agricultura & 1.128 & 8.088 .561 & 919.993 & -437.282 & -384.426 & -52.856 \\
\hline Indústria & 13.808 & 258.793 .211 & 45.174 .117 & -603.446 & 966.900 & -1.570 .346 \\
\hline Comércio & 30.307 & 412.324 .746 & 55.975 .019 & 5.585 .805 & 5.628 .495 & -42.689 \\
\hline Serviço & 24.469 & 206.781 .666 & 49.526 .587 & 1.806 .945 & 3.608 .785 & -1.801 .840 \\
\hline Total & 69.712 & 885.988 .184 & 151.595 .715 & 6.352 .023 & 9.819 .754 & -3.467 .731 \\
\hline
\end{tabular}

Tabela 3. Variações (\%) dos anos-base 2008-2009 em relação a 2005-2007

\begin{tabular}{|c|c|c|c|c|c|c|}
\hline Setor & $\begin{array}{c}\text { Quantidade de } \\
\text { empresas }\end{array}$ & Receita bruta & Lucro bruto & Lucro fiscal & Lucro contábil & $\begin{array}{l}\text { Diferença lucros } \\
\text { fiscal e contábil }\end{array}$ \\
\hline Agricultura & 1.128 & $3,43 \%$ & $-0,84 \%$ & $21,48 \%$ & $-42,29 \%$ & $81,57 \%$ \\
\hline Indústria & 13.808 & $14,25 \%$ & $14,01 \%$ & $-150,13 \%$ & $-53,28 \%$ & $-81,37 \%$ \\
\hline Comércio & 30.307 & $20,93 \%$ & $25,47 \%$ & $62,90 \%$ & $55,01 \%$ & $78,89 \%$ \\
\hline Serviço & 24.469 & $9,25 \%$ & $14,72 \%$ & $-31,01 \%$ & $-11,06 \%$ & $-25,27 \%$ \\
\hline TOTAL & 69.712 & $15,88 \%$ & $18,12 \%$ & $-5,13 \%$ & $3,49 \%$ & $-24,15 \%$ \\
\hline
\end{tabular}

As tabelas 1 a 3 evidenciaram importantes indicadores para economia nacional, retratada pela contabilidade através da receita bruta, do lucro bruto e dos resultados fiscal e contábil, bem como da dimensão da diferença entre essas duas últimas variáveis.

De modo geral, a empresa optava pelo RTT quando tinha valores de receitas superiores a despesas mais custos, todos instituídos pelos novos critérios contábeis estabelecidos pelas Leis $\mathrm{n}^{\circ} 11.638 / 2007$ e 11.941/2009. De forma inversa, não efetivaria a opção por esse regime quando as despesas mais custos fossem maiores que as receitas. Por exemplo, uma empresa que apurou uma despesa em decorrência da redução ao valor recuperável de seu ativo imobilizado - e essa foi a única operação abrangida pelos normativos que entraram em vigor a partir da vigência da Lei $\mathrm{n}^{\circ} 11.638 / 07$-, de modo geral, não optaria pelo RTT, pois seria beneficiada por uma despesa que reduziria o seu lucro fiscal, que é a base de cálculo para o pagamento do IRPJ e CSLL ${ }^{20}$. Entretanto, numa situação oposta, qual seja, se o contribuinte registra uma receita

$20 \mathrm{O}$ artigo $6^{\circ}$ do Decreto-lei 1.598/1978 prevê que o lucro líquido, da contabilidade financeira, é apurado com base na lei comercial. oriunda de uma doação governamental, atendendo aos preceitos do CPC 07 - e este é o único resultado previsto pelas novas normas contábeis da Lei $\mathrm{n}^{\circ} 11.638 / 07$-, em princípio faria a opção pelo RTT, com vistas a neutralizar os efeitos dessa nova receita para fins tributários.

A tabela 3 evidencia o aumento do lucro contábil em $3,49 \%$ contra a redução de $5,13 \%$ do lucro fiscal ocasionou uma diminuição de $24,15 \%$ na diferença entre eles - a literatura internacional chama de BTD, conforme citado no item 2.3 - e pode indicar também uma redução da carga tributária. No entanto, seriam necessários estudos que investigassem essa possibilidade, uma vez que o aumento do lucro fiscal, em escala bem inferior à elevação do resultado contábil, pode ter se originado, por exemplo, de ajustes temporários ${ }^{21}$ - quando ocorre um descompasso no momento do reconhecimento de uma receita ou despesas no lucro contábil e fiscal -, no planejamento tributário ou, até mesmo, na evasão fiscal.

21. Há também os ajustes permanentes, mas, em princípio, no caso desse estudo, não teriam efeito porque as novas normas contábeis também foram aplicadas às tributárias, no caso das empresas não optantes. 
Mas há outra evidência que indica que as empresas que não optaram pelo RTT pagaram valores menores de IRPJ e de CSLL em 2008-2009 - em decorrência das novas normas contábeis -, dado que a variação, de $15,88 \%$ da receita bruta, foi superior à do lucro fiscal base de cálculo para a aplicação das alíquotas do IRPJ e CSLL -, que foi de menos 5,13\%. O efeito da crise da economia global - que afetou, principalmente, o segundo semestre de 2008 e o primeiro de 2009 -, nos resultados fiscal e contábil, foi minorado através dessa correlação com as variáveis receita e lucro brutos.

No entanto, o teste de Wilcoxon apresentou significância estatística ( $p$-value $=0,000)$ para justificar que o lucro fiscal médio de 2008-2009 foi inferior ao do período anterior, 2005-2007 ( $\mathrm{z}=-31,950)$, conforme tabela 4 , a seguir.

Analisando as variações sob a ótica dos quatro setores, cabe destacar a variação na receita bruta de $20,93 \%$ no comércio e de apenas $3,43 \%$ na agricultura. A variação negativa de $5,13 \%$ no lucro fiscal foi, preponderantemente, produzida pelo setor do comércio, que aumentou $62,9 \%$. Mas a indústria divergiu radicalmente dos demais setores com uma redução de $150,13 \%$.

O resultado contábil aumentou 3,49\%, aumento este também "puxado" pelo comércio, que cresceu 55,01\%. Mais uma vez, o setor industrial variou no sentido contrário, com uma queda de $53,28 \%$.

Destarte, a diferença entre os lucros fiscal e contábil entre os períodos 2008-2009 e 2005-2007, que variou negativamente em torno de $24,15 \%$, foi influenciada, principalmente, pelo setor da indústria, que apresentou uma redução de cerca de $81,37 \%$. Importante também frisar que nenhum setor apresentou diferença positiva nesses dois períodos, ou seja, o lucro fiscal foi sempre inferior ao contábil.

Tabela 4. Resultado do teste de Wilcoxon

\begin{tabular}{c|c|c|c}
\hline \multicolumn{5}{c}{ Rank } \\
\hline Negative Rank & 29765 & 34447,22 & $1,03 \mathrm{E}+09$ \\
\hline Positive Ranks & 39307 & 34604,1 & $1,36 \mathrm{E}+09$ \\
\hline Ties & & 640 & \\
\hline Total & & 69712 & \\
\hline
\end{tabular}

a. Lucro fiscal -médio 2008-2009 < Lucro Fiscal Médio 2005-2005

b. Lucro fiscal médio 2008-2009 > Lucro Fiscal Médio 2005-2007

c. Lucro fiscal médio 2008-2009 = Lucro Fiscal Médio 2005-2007

\begin{tabular}{|c|c|c|c|c|}
\hline \multicolumn{5}{|c|}{ Test Statistic ${ }^{b}$} \\
\hline \multicolumn{5}{|c|}{$\begin{array}{l}\text { LUCRO FISCAL - MÉDIA ACs } 09 \text { E } 08 \text { (R\$MIL) } \\
\text { LUCRO FISCAL - MÉDIA ACs } 07 \text { E } 05 \text { (R\$MIL) }\end{array}$} \\
\hline \multicolumn{2}{|c|}{$\mathrm{Z}$} & \multicolumn{3}{|c|}{$-31,950^{\mathrm{a}}$} \\
\hline \multicolumn{2}{|c|}{ Asymp. Sig. (2-tailed) } & & & \\
\hline \multicolumn{5}{|c|}{$\begin{array}{l}\text { a Based on negative ranks. } \\
\text { bWilcox on Signed Rank Test }\end{array}$} \\
\hline \multicolumn{5}{|c|}{ Descriptive Sstatistics } \\
\hline & $\mathrm{N}$ & Minimum & Maximum & Mean \\
\hline $2005-2007$ & 69712 & -1010177 & 880711,2 & 96,0401 \\
\hline 2008-2009 & 69712 & -598615 & 961495,4 & 91,118 \\
\hline
\end{tabular}

\subsection{Análises dos anos 2008 e 2009}

Tabela 5. Resultados por setor no ano 2008 com valores médios em R\$ mil

\begin{tabular}{l|c|c|c|c|c|c}
\hline \multicolumn{1}{c|}{ Setor } & $\begin{array}{c}\text { Quantidade de } \\
\text { empresas }\end{array}$ & Receita bruta & Lucro bruto & Lucro fiscal & $\begin{array}{c}\text { Lucro contábil } \\
\text { fiscal e contábil }\end{array}$ \\
\hline Agricultura & 1.128 & 7.967 .262 & 999.444 & -356.654 & -370.559 & 13.906 \\
\hline Indústria & 13.808 & 258.710 .657 & 44.442 .077 & -698.797 & -2.477 .596 & 1.778 .799 \\
\hline Comércio & 30.307 & 400.181 .926 & 53.868 .953 & 5.542 .837 & 4.774 .609 & 768.229 \\
\hline Serviço & 24.469 & 208.348 .171 & 47.629 .911 & 1.704 .545 & 648.680 & 1.055 .866 \\
\hline TOTAL & 69.712 & 875.208 .016 & 146.940 .384 & 6.191 .932 & 2.575 .133 & 3.616 .799 \\
\hline
\end{tabular}


Tabela 6. Resultados por setor no ano 2009 com valores médios em R\$ mil

\begin{tabular}{|c|c|c|c|c|c|c|}
\hline Setor & $\begin{array}{c}\text { Quantidade de } \\
\text { empresas }\end{array}$ & Receita bruta & Lucro bruto & Lucro fiscal & Lucro contábil & $\begin{array}{l}\text { Diferença lucros } \\
\text { fiscal e contábil }\end{array}$ \\
\hline Agricultura & 1.128 & 7.331 .491 & 721.477 & -364.496 & -238.168 & -126.327 \\
\hline Indústria & 13.808 & 244.305 .895 & 42.653 .200 & -161.018 & 4.265 .842 & -4.426 .860 \\
\hline Comércio & 30.307 & 393.197 .756 & 52.663 .313 & 5.593 .992 & 6.439 .994 & -846.002 \\
\hline Serviço & 24.469 & 195.614 .339 & 46.706 .054 & 1.586 .870 & 6.205 .040 & -4.618 .170 \\
\hline TOTAL & 69.712 & 840.449 .481 & 142.744 .044 & 6.655 .349 & 16.672 .708 & -10.017 .359 \\
\hline
\end{tabular}

Tabela 7. Variações percentuais de 2009 em relação a 2008

\begin{tabular}{c|c|c|c|c|c|c}
\hline Setor & $\begin{array}{c}\text { Quantidade de } \\
\text { empresas }\end{array}$ & Receita bruta & Lucro bruto & Lucro fiscal & $\begin{array}{c}\text { Lucro contábil } \\
\text { Diferença lucros } \\
\text { fiscal e contábil }\end{array}$ \\
\hline Agricultura & 1.128 & $-7,98 \%$ & $-27,81 \%$ & $-2,20 \%$ & $35,73 \%$ \\
\hline Indústria & 13.808 & $-5,57 \%$ & $-4,03 \%$ & $76,96 \%$ & $272,18 \%$ & $-1008,46 \%$ \\
\hline Comércio & 30.307 & $-1,75 \%$ & $-2,24 \%$ & $0,92 \%$ & $34,88 \%$ & $-210,12 \%$ \\
\hline Serviço & 24.469 & $-6,11 \%$ & $-1,94 \%$ & $-6,90 \%$ & $856,56 \%$ & $-537,38 \%$ \\
\hline TOTAL & 69.712 & $-3,97 \%$ & $-2,86 \%$ & $7,48 \%$ & $547,45 \%$ & $-376,97 \%$ \\
\hline
\end{tabular}

As tabelas 5 a 7 acima retratam as variáveis estudadas nos anos 2008 e 2009 sob a vigência das novas normas contábeis, instituídas pela Lei $\mathrm{n}^{\circ} 11.638 / 07$, que, especificamente na tabela 7 , fazem aflorar significativa variação de 547,45\% no lucro contábil em contraposição às demais variáveis.

A dificuldade para se analisar os anos de 2008 e 2009 reside, pelo menos, em três motivos: i) a crise econômica global que abarcou, principalmente, o período entre o segundo semestre do primeiro ano - 2008 - e o primeiro semestre de 2009, mas que não produziu os mesmos efeitos em cada um desses anos; ii) a entrada em vigor, a partir de 2008, de nove normativos emitidos pelo CPC, com aprovação legal e dos órgãos reguladores, que modificaram os critérios de reconhecimento nos resultados contábil e fiscal; iii) mesmo reduzindo-se os 69.712 contribuintes para uma amostra com as maiores variações, muito tempo seria necessário para realizar sua análise.

A discrepância na variação de $547,45 \%$ do lucro contábil entre 2008 e 2009 foi surpreendente, pois as novas regras contábeis eram as mesmas para os anos 2008-2009 e, em princípio, não foram causados, preponderantemente, pela crise internacional, pelo fato de a receita e o lucro brutos não variarem na mesma proporção - foram de negativos em 3,97\% e $2,86 \%$, respectivamente ${ }^{22}$. Contribuiu também o fato de o resultado fiscal ter variado de forma muito distinta daquele que ocorreu com o lucro contábil, pois as novas receitas e despesas não deveriam ocasionar tamanha diferença ${ }^{23}$ nos lucros contábil e tributário, em virtude de esses contribuintes não terem optado pelo RTT. Discriminando as alterações pelos setores, todas foram positivas onde as maiores foram apresentadas pelos

22. Apesar de essa crise causar impacto na receita e no lucro brutos e no lucro contábil e dificultar a análise, uma diferença nesse patamar não é justificada apenas por esse motivo.

23. Alguma diferença era esperada em virtude dos ajustes temporários - explicado nos comentários da Tabela 3 - Variações (\%) dos anos-base 2008-2009 em relação à 2005-2007 -, mas não nessa proporção.. setores serviços, com $856,55 \%$, e indústria, que ostentou o percentual de $272,18 \%$.

O lucro fiscal de 2008 por sua vez, foi muito próximo daquele que se obteve em 2009, como também da média de 2005-2007, exceto o da indústria, que aumentou $76,96 \%$. Isso explica o descompasso entre a diferença dos lucros fiscal e contábil de 2008 (209.651 reais) com os de 2009 (- 649.243 reais).

A relação do lucro fiscal com a receita bruta é homogênea nesses períodos $(0,79 \%$ em $2009,0,71 \%$ em 2008 e $0,88 \%$ em 2005-2007), como também o é com o lucro bruto $(4,66 \%, 4,21 \%$ e $5,22 \%$, respectivamente para esses períodos). Dessa forma, apesar de não se eliminarem os efeitos da crise internacional, conforme item (i) acima, essa correlação do lucro fiscal com a receita e o lucro brutos reduz um pouco seu impacto.

Já a comparação do lucro contábil com a receita bruta é mais heterogênea, dado que apresenta 1,98\%, em 2009; 0,29\%, em 2008; e 1,24\%, em 2005-2007, como também o é com o lucro bruto $(11,68 \%, 1,75 \%$ e $7,39 \%$, nesses mesmos períodos). $\mathrm{O}$ ano de 2008 é o mais afastado dos demais períodos.

\subsection{Efeitos da IN RFB $n^{\circ} 1.023 / 10$}

\subsubsection{Comparação das DIPJ retificadoras de 2008 e 2007}

No ano-base 2007, 5.506 DIPJ foram retificadas, durante o período entre 26/12/2008 e 14/09/2009, enquanto no ano-calendário 2008, 7.660 empresas promoveram alterações, no período de 13/04/2010 até $31 / 12 / 2010$, na DIPJ originalmente, cujo prazo se concluía em 16/10/2009. Portanto, há evidências sobre a importância da IN RFB $\mathrm{n}^{\circ} 1.023$, publicada em 13/04/2010, pois o ano de 2008 apresentou um número $39 \%$ superior àquele relativo às solicitações de alteração 
da DIPJ, apresentadas no período de 26/12/2008 a 14/09/2009. Com base nesses dados, existem indícios de que essa Norma apresentou o efeito esperado e tanto pleiteado pelos contribuintes, que, com razão, tinham cenários obscuros em 16/10/2009, primeira data estabelecida para a opção pelo RTT, justificados, por exemplo, pelo exercício social de 2009 ainda não encerrado e pela insegurança acerca da interpretação que a Receita Federal do Brasil daria às consequências fiscais resultantes das novas normas contábeis.

\subsubsection{Resultado das empresas que alteraram a opção pelo RTT em 2008}

No ano-calendário 2008, das 95.059 empresas que não optaram pelo RTT, apenas 973 retificaram, entre 13/04/2010 a 31/12/2010, a DIPJ original, e passaram para optante desse regime. Esse número é baixo, pois representa apenas $1 \%$ dos não optantes de lucro real. Mas a maior justificativa para classificá-lo como reduzido é que a data-limite para a opção da DIPJ originalmente apresentada foi em 16/10/2009, e, como essa decisão valeria cumulativamente para o biênio 2008-2009 e este ano ainda não estava encerrado, seria exigida muita predição dos resultados contábil e fiscal, bem como dos efeitos das novas normas contábeis. Isso pode ter alguma relação com a boa qualidade das análises originais, nesse ambiente de incertezas, pelo menos para a decisão quanto à opção ou não pelo RTT. Porém, não foi objetivo deste trabalho atestar a qualidade do trabalho dos contadores.

A tabela abaixo representa o resultado das retificações da DIPJ promovido pelos 973 contribuintes citados no parágrafo anterior. Apesar de não ter sido possível correlacionar o lucro fiscal com a receita e o lucro brutos (as duas últimas variáveis não foram extraídas da DIPJ original) com o intuito de investigar a evolução da carga tributária, há indícios de que houve redução da base fiscal, pois o resultado fiscal aumentou $60 \%$ menos do que o lucro contábil. É apenas um indicador, todavia seria mais robusto compará-lo, também, com a receita e lucro brutos.

Tabela 8. Resultados das DIPJ retificadas de não para optantes RTT

\begin{tabular}{|c|c|c|c|}
\hline DIPJ & $\begin{array}{l}\text { Lucro fiscal } \\
\text { (em R\$ mil) }\end{array}$ & $\begin{array}{c}\text { Lucro } \\
\text { contábil } \\
\text { (em R\$ mil) }\end{array}$ & $\begin{array}{c}\text { Diferença lucro } \\
\text { s fiscal e contábi } \\
\text { (em R\$ mil) }\end{array}$ \\
\hline Original & 163.408 & 128.469 & 34.939 \\
\hline Retificadora & 274.720 & 268.649 & 6.071 \\
\hline $\begin{array}{l}\text { Diferença } \\
\text { DIPJ } \\
\text { retificadora } \\
\text { e original }\end{array}$ & 111.313 & 140.180 & -28.867 \\
\hline Variação \% & $68,12 \%$ & $109,12 \%$ & $-82,62 \%$ \\
\hline
\end{tabular}

Apenas 11 contribuintes informaram valores diferentes de zero nas linhas de ajuste de RTT (linhas 2 e 3 da ficha 9) na DIPJ do ano-base 2008, retificadora, com um ajuste total negativo de 6,5 milhões de reais. Essa quantidade é considerada reduzida porque, de forma geral, opta-se por esse regime para neutralizar o resultado positivo das receitas menos as despesas (das novas normas contábeis) - conforme exemplificado no item 4.1 -, mesmo considerando-se que algumas empresas não tenham anulado esses ajustes do RTT, em 2008, mas o tenham promovido em 2009 (a opção era obrigatória para esse biênio).

\section{CONCLUSÕES}

A análise o efeito do RTT nos resultados fiscal e contábil dos anos de 2008 e 2009, comparando-os com a média no período de 2005 a 2007, para as empresas de lucro real que não optaram por esse regime, com discriminação pelos setores agricultura, comércio, indústria e serviços, foi resumido nas tabelas 1 a 3 do item 4.1 - Resultados dos anos 2005-2007 e 2008-2009 - onde se destaca a suposição de que essas empresas pagaram menos IRPJ e CSLL em 2008-2009, em decorrência das novas normas contábeis, principalmente, em decorrência da variação positiva da receita e do lucro brutos, que foi de $15,8 \%$ e $18,1 \%$, enquanto o lucro fiscal - base de cálculo para a aplicação das alíquotas desses dois tributos - ter sido bem inferior, ou seja, negativo em 5,1\%.

As evidências desses efeitos na carga tributária ${ }^{24}$, foram melhor justificadas pelo teste de Wilcoxon, que apresentou significância estatística para o lucro fiscal médio de 2008-2009 ter sido inferior ao do período anterior, 2005-2007 e são valiosas para subsidiar possíveis modificações na legislação tributária, caso se deseje maior proximidade com a perspectiva econômica - e menor com a civil -, tal como ocorre com a contabilidade societária, após sua convergência para as normas contábeis internacionais. Mas é essencial frisar, que tal mudança de perspectiva deve respaldar-se em base legal, em harmonia com conceito de renda esculpido na Carta Magna e no artigo 43 do CTN.

Esses resultados também foram importantes para evidenciar as variações em relevantes indicadores econômicos como a receita bruta, o lucro bruto e os resultados fiscal e contábil, bem como a dimensão da diferença entre essas duas últimas variáveis em menos $24,1 \%$. Isso teve origem no aumento de $3,4 \%$ no lucro contábil, que foi superior à variação negativa de 5,1\% no resultado tributário.

Na comparação entre os anos 2008 e 2009, conforme resultados nas tabelas 5 a 7 do item 4.2 , surpreendeu a variação positiva de $547,4 \%$ do lucro contábil, pois as novas regras contábeis foram as mesmas para os anos 2008-2009 e, em princípio, não seriam causados, preponderantemente, pela crise internacional, pelo fato de a receita e de o lucro brutos não terem variado na mesma proporção (foram de $-3,97 \%$ e $-2,86 \%$, nessa ordem). Contribuiu também o fato de o resultado fiscal ter variado de forma tão distinta - o lucro fiscal não apresentou toda essa distorção, aumentando apenas $7,4 \%$ - pois as novas receitas e despesas não deveriam ocasionar tanta diferença nos lucros contábil e tributário, em virtude de esses contribuintes não terem optado pelo RTT. Importante também frisar que nenhum setor apresentou diferença positiva nesses dois períodos, ou seja, o lucro fiscal foi sempre inferior ao contábil, bem como a variação positiva de $76,9 \%$ no lucro fiscal da indústria e de $856,5 \%$ no resultado contábil do setor de serviços.

24. A amostra examinada representou $48 \%$ das empresas de lucro real. 
Quanto ao objetivo de averiguar a quantidade de empresas de lucro real que não optou pelo RTT e sua participação no total de empresas desse regime de apuração de lucro, elas totalizaram 95.059 no ano-calendário 2008, representando $65 \%$ das 146.213 empresas de lucro real. Isso evidencia que para a maioria das empresas desse regime tributário as novas normas contábeis instituídas a partir da Lei 11.638/07 não representaram aumento na carga tributária do IRPJ e CSLL.

A análise da eficiência da IN RFB n ${ }^{\circ} 1.023$, conforme item 4.3.1, indica que 7.660 empresas de lucro real retificaram suas DIPJs do ano-calendário 2008, entre 13/04/2010 e 31/12/2010, número este superior a dos 5.506 contribuintes desse regime tributário que modificaram suas Declarações do ano-base anterior (2007), no período de 26/12/2008 a 14/09/2009. Dessa forma, os resultados destacaram a necessidade da edição dessa norma, em consequência, preponderantemente, do pouco tempo para compreensão dos efeitos dessas novas normas no resultado contábil e fiscal; do desconhecimento do impacto causado no último trimestre de 2009, nos lucros tributário e contábil - a opção original pelo RTT foi em 16/10/2009; e do desconhecimento da interpretação feita pela Receita Federal do Brasil de algumas questões não regulamentadas por esse órgão.

Quanto à mudança na opção do RTT de não para sim, descrita no item 4.3.2, apenas 973 empresas (1\% de um total de 95.059 não optantes) retificaram a DIPJ, indicando um bom trabalho preditivo dos contadores, pois na opção original em 16/10/2009 muitas dúvidas existiam conforme já destacado neste trabalho. Essas alteracões ocasionaram o lucro contábil aumentado em $109,1 \%$ (retificou para 268 milhões e 649 mil reais) e o resultado fiscal, em $68,1 \%$ (alterou para 274 milhões e 720 mil reais). Todavia o que mais chamou a atenção foi que apenas 11 contribuintes informaram valores de ajuste do RTT na DIPJ (ficha 9, linhas 2 e 3), com um valor total negativo de 6,5 milhões de reais.

Os resultados evidenciados por esta pesquisa foram representativos, pois a amostra contemplou $73 \%$ das empresas de lucro real não optantes pelo RTT e $48 \%{ }^{25}$ do total das empresas desse regime tributário, no biênio 2008-2009. Entretanto, como a partir de 2010 o RTT tornou-se obrigatório para todos, sem a alternativa de opção, e, além disso, novas normas contábeis, elaboradas pelo CPC - e validadas pelos órgãos reguladores de contabilidade, como CVM e CFC - entraram em vigor a partir de 2010, bem como a edição de novas legislações fiscais (Instrução Normativa 1397/13 e Medida Provisória 627/13), novos estudos são aguardados, pois, inquestionavelmente, serão muito importantes para completar este trabalho, bem como investigar os efeitos dessas novas normas contábeis sob uma perspectiva macroeconômica.

\section{REFERÊNCIAS}

BRASIL. Decreto-lei n. 1.598, de 26/12/1977. Diário Oficial da União. Congresso Nacional. Brasília, DF, 1977.

25. Esse é o percentual que representa as 69.712 empresas da amostra em relação ao total de empresas de lucro real (146.213). O total de não optantes foi de 95.059, até 31/12/2010.
Instrução Normativa RFB n. 1.023, de 13/04/2010. Diário Oficial da União. Poder Executivo. Brasília, DF, 2010.

Instrução Normativa RFB n. 1.397, de 16/09/2013. Diário Oficial da União. Poder Executivo. Brasília, DF, 2013.

Lei n. 6.404, de 17/12/1976. Diário Oficial da União. Congresso Nacional. Brasília, DF, 1976.

Lei n. 11.638, de 28/12/2007. Diário Oficial da União. Congresso Nacional. Brasília, DF, 2007.

Lei n. 11.941, de 27/05/2009. Diário Oficial da União. Congresso Nacional. Brasília, DF, 2009.

Medida Provisória n. 449, de 04/12/2008. Diário Oficial da União. Poder Executivo. Brasília, DF, 2008.

Medida Provisória n. 627, de 11/11/2013. Diário Oficial da União. Poder Executivo. Brasília, DF, 2013.

CALIJURI, Mônica S.S. As novas normas de convergência contábeis e seus reflexos para os contribuintes. In: MOSQUERA, Roberto Q; LOPES, Alexsandro B. (coordenadores). Controvérsias jurídico-contábeis (aproximações e distanciamentos), $2^{\circ}$ volume. São Paulo: Dialética, 2011.

CARVAlho, Paulo B. Curso de Direito Tributário. São Paulo: Saraiva, 2000.

CHAN, K. Hung; LIN, Kenny Z.; TANG, Feng. Tax effects of book-tax conformity, financial reporting incentives, and firm size. Journal of International Accounting Research. 2013, Vol. 12, n.2, p. 1-25.

COMITÊ DE PRONUNCIAMENTOS CONTÁBEIS - CPC. Pronunciamento Conceitual Básico: Estrutura Conceitual para a Elaboração e Apresentação das Demonstrações Contábeis. Brasília, 2008.

COMITÊ DE PRONUNCIAMENTOS CONTÁBEIS - CPC. Pronunciamentos técnicos CPC 01, 02, 04, 06, 07, 08, 10, 12, 13, 14, 30. Brasília, 2010. EBERHARTINGER, Eva; KLOSTERMANN, Margret. What if IAS/IFRS were a tax base? new empirical evidence from an Austrian perspective. Accounting in Europe. 2007, Vol. 4, p. 141-168.

FORMIGONI, Henrique et al. Diferença entre o lucro contábil e lucro tributável: uma análise sobre o gerenciamento de resultados contábeis e gerenciamento tributário nas companhias abertas brasileiras. Brazilian Business Review - BBR 2009, Vol. 6, nº 1, p. 44-61.

GEE, Maria; HALLER, Axel; NOBES, Christopher. The influence of tax in IFRS consolidated statements: the convergente of Germany and the UK. Accounting in Europe. 2010, Vol. 7, n.1, p. 97-122.

GIL, A. C. Como elaborar projetos de pesquisa. São Paulo: Atlas, 2002.

HAVERALS, Jacqueline. IAS/IFRS in Belgium: quantitative analysis of the impact $\mathrm{n}$ the tax burden of companies. Journal of International Accounting, Auditing and Taxation. 2007, Vol. 16 , p. $69-89$. 
HENDRIKSEN, Eldon S.; BREDA, Michael F. Van. Teoria da Contabilidade. São Paulo: Atlas, 2007.

ISTRATE, Costel. Impact of IFRS on Romanian accounting and tax rules for fixed tangible assets. Accounting and Management Information Systems. 2012, Vol. 11, n², p.243-263.

KAGER, Rebekka; SCHANZ, Deborah; NIEMANN, Rainer. Estimation of tax values based on IFRS information: an analysis of German DAX30 and Austrian ATX listed companies. Accounting in Europe. 2011, Vol. 8, nº 1, p. 89-123.

KARAMPINIS, Nikolaos I.; HEVAS, Dimosthenis L. Effects of IFRS adoption on tax-induced incentives for Financial Earnings Management: evidence from Greece. The International Journal of Accounting. 2013, Vol. 48, p. 218-247.

KIRSCH, Hanno; OLSSON, Stefan. Financial Accounting and Tax Accounting: Germany and Sweden as Examples. Skattenytt SN, 2008. p. 746-757. Disponível em: <http://www.skattenytt. se/pdf/SN\%2012\%202008\%20\%20s.\%20746-757. pdf $>$. Acesso em 01 nov. 2013.

LOPES, Alexsandro B; MARTINS, Eliseu. Teoria da Contabilidade: Uma Nova Abordagem. São Paulo: Atlas, 2005.

MADALINA, Girbina; NADIA, Albu; CATALIN, Albu. Implications of the application of IFRS For SMEs in Romania on taxable and distributable profit. Annals of Faculty of Economics, University of Oradea. 2011, Vol. 1, n.2, p. 517-522.

MARTINS, Gilberto; THEÓPHILO, Carlos R. Metodologia da investigação científica para ciências sociais aplicadas. 2. ed. São Paulo: Atlas, 2009.

MILLS, L. Book-tax differences and Internal Revenue Service adjustments. Jounal of Accounting Research 1998, n 36(2), p. 343-356.

MOSQUERA, Roberto Q; LOPES, Alexsandro B. (coordenadores). Controvérsias jurídicocontábeis (aproximações e distanciamentos). São Paulo: Dialética, 2010.

ROOD, Joan; KINNEY, Laura. IFRS implications for income taxes. Financial Executive. October 2008, p. $52-54$.

TANG, Tanya Y.H. Book-Tax Differences, a Proxy for Earnings Management and Tax Management Empirical Evidence from China. SSRN 19/11/2005. Disponível em <http://papers.ssrn.com/sol13/ papers.cfm?abstract id $=872389>$, acessado em 23/10/2010.

TZOVAS, C. Factors Influencing a Firm's Accounting Policy Decisions when Tax Accounting and Financial Accounting Coincide. Managerial Auditing Journal 4, p. 372-386, 2006.

WEFFORT, Elionor F.J. O Brasil e a harmonização contábil internacional: influências dos sistemas jurídicos e educacional, da cultura e do mercado. São Paulo: Atlas, 2005.

ZIMMERMANN, Jochen; GONCHAROV, Igor. Earnings management when incentives compe: the role of tax accounting in Russia. SSRN
18/02/2005. Disponível em <http://papers.ssrn. $\mathrm{com} / \mathrm{sol} /$ papers.cfm? abstract_id=622640>, acessado em 23/10/2010. 